J. Lake Sci. (湖泊科学), 2011, 23(4): 642-648

http: //www.jlakes.org. E-mail: jlakes@niglas. ac.cn

(c) 2011 by Journal of Lake Sciences

\title{
基于土地利用动态变化的太湖地区景观生态风险评价*
}

\author{
许 妍 $^{1,2}$, 高俊峰 $^{1 * *}$, 高永年 ${ }^{1}$ \\ (1: 中国科学院南京地理与湖泊研究所,南京 210008) \\ (2: 中国科学院研究生院, 北京 100049 )
}

\begin{abstract}
摘 要: 在 GIS 和 RS 技术支持下, 以遥感数据和土地利用数据为基础, 以行政区划为评价单元, 定量分析太湖地区 $1990-$ 2008 年土地利用变化及其转化关系; 从土地利用变化和景观结构角度构建景观生态风险评价模型, 定量评价了研究区内 景观生态风险的时空动态变化特征. 结果表明: 太湖地区景观生态风险分布与区内土地利用方式和强度具有较高关联. 景观生态风险整体呈上升趋势, 高生态风险区范围不断扩大; 受自然特征和社会经济发展影响, 景观生态风险空间分异 显著, 较低风险区主要分布于以芳溪为主的山地丘陵区, 中等风险区主要分布于农业发达的平原区, 较高风险区及高风 险区主要集中于沿湖经济发达区. 不同区域景观生态风险来源存在一定差异, 各用地类型对生态风险的贡献率亦不尽相 同, 就全区而言, 景观生态风险主要来源于耕地和建设用地, 但随着社会经济不断发展, 来自水域和林地的生态风险比例 越来越大.
\end{abstract}

关键词: 土地利用; 景观; 生态风险评价;太湖地区

\section{Landscape ecological risk assessment in the Taihu region based on land use change}

\author{
XU Yan ${ }^{1,2}$, GAO Junfeng ${ }^{1} \&$ GAO Yongnian ${ }^{1}$ \\ (1: Nanjing Institute of Geography and Limnology, Chinese Academy of Sciences, Nanjing 210008, P. R. China) \\ (2: Graduate School of the Chinese Academy of Sciences, Beijing 100049, P. R. China)
}

\begin{abstract}
The quantitative analysis of the land use change and its transformation relationship in the Taihu region during 1990 2008 was put forward, using GIS and RS technologies, based on the remote sensing data and land use data, taking the administrative division as the assessment units. The assessment model comprising a landscape disturbance index and a land use sensitivity index was established on the base of land use change and landscape perspective to assess the landscape ecological risk characteristics of temporal and spatial change in study area. The results showed that the distribution of ecological risk had higher associated with the intensity and pattern of land use change. As a whole, the landscape ecological risk had been rising in the past 18 years; the area of high ecological risk was expanding. Due to the physical characteristics and social economy, the spatial variation of landscape ecological risk was significant. The low risk areas distributed mainly in the hilly and mountainous areas, the medium risk areas was mainly in the agriculture developed plain area, and the higher and highest risk areas distributed at the economically developed areas around the lake. The sources of landscape ecological risks were different, and variable land use types also had different risks. The farmland and construction land were the main risk source of the whole region. As the regional development, the ecological risk from the water and woodland were increasing steadily.
\end{abstract}

Keywords: Land use change; landscape; ecological risk assessment; Taihu region

生态风险是指种群、生态系统或整个景观的生态功能受到外界胁迫, 从而在目前和将来对该系统健康、 生产力、遗传结构、经济价值和美学价值产生不良影响的一种状况 ${ }^{[1]}$. 区域生态风险评价是在区域尺度上描 述和评估区域的环境污染、人为活动或自然灾害对生态系统及其组分产生不利作用的可能性和危害程度,

* 国家水体污染控制与治理科技重大专项项目 (2008ZX07101-014-01、2008ZX07526-007) 和科技部基础性工作 专项项目 (2008CB418106) 联合资助. 2010-08-16 收稿; 2010-12-01 收修改稿. 许妍, 女, 1981 年生, 博士; E-mail:xuyandlls@163.com.

** 通讯作者; E-mail: gaojunf@ niglas. ac. cn. 
其目的在于为区域风险管理提供理论和技术支持 ${ }^{[2]}$. 与一般生态风险评价不同, 区域生态风险评价更加重 视空间要素配置对生态风险过程的影响, 其主要标志是考虑了景观空间结构对暴露过程和危害过程的影 响 ${ }^{[3-4]}$. 景观作为具有高度空间异质性的区域, 它是由相互作用的景观要素或生态系统以一定的规律组成, 其生态系统的变化首先表现在景观结构组分或要素的空间结构、相互作用以及功能的变化和演替上 ${ }^{[5]}$. 在 人为活动占优势的景观内, 土地利用反映了人类对自然生态系统的影响方式及程度, 其产生的生态影响具 有区域性和累积性特征, 可以直观地反映在生态系统的结构和组成上 ${ }^{[6-7]}$. 因此, 在缺乏生态监测资料的历 史积累时, 从土地利用动态变化视角对景观格局特征进行研究是揭示大尺度区域综合生态状况及空间变异 的有效手段.

近年来, 国内外学者通过建立景观格局与生态风险关系模型对景观生态风险进行了定量评价 ${ }^{[1,8-10]}$. 曾 辉等根据不同时段景观要素的结构特征构建生态风险评价指标 ${ }^{[1]}$. Kapustka 等运用景观生态方法进行了生 态风险评价并提出风险管理对策 ${ }^{[8]}$. Liu 等 ${ }^{[9]}$ 以土壤侵蚀强度和生态脆弱度指示潜在的生态风险. 此外, 一 些学者对县市 ${ }^{[11-12]} 、$ 城乡交错带 ${ }^{[13]} 、$ 河流 $^{[14]}$ 等不同区域尺度的景观生态风险进行了个案研究,但关于太湖 流域这种大尺度的研究较少 ${ }^{[15]}$. 本研究以太湖主要出人湖河流覆盖区为例, 在土地利用变化基础上, 以景观 格局指数为评价指标, 揭示了太湖流域景观生态风险的时空演化特征及土地利用对景观生态风险的潜在影 响, 以期为生态建设与生态恢复提供决策支持.

\section{1 研究区域与数据来源}

\section{1 研究区域概况}

太湖 $\left(30^{\circ} 7^{\prime} 19^{\prime \prime}-32^{\circ} 14^{\prime} 56^{\prime \prime} \mathrm{N}, 119^{\circ} 3^{\prime} 1^{\prime \prime}-120^{\circ} 53^{\prime} 34^{\prime \prime} \mathrm{E}\right)$ 区域面积为 $21603 \mathrm{~km}^{2}$, 是太湖主要出人湖河流覆 盖区,包括江苏省和浙江省的 14 个县市区, 总人口约 1483.75 万人. 该区地表起伏相对较大, 高程介于 $0-$ $1567 \mathrm{~m}$ 之间,地形自北向南过渡明显; 河网密布, 湖泊众多,主要包括洮滆水系、苕溪水系等人湖水系及锡澄 运河、望虞河等区域性沿江水系,湖泊主要有洮湖、滆湖、阳澄湖等. 区内水热分布不均,南北差异较大,植被 以次生性自然植被为主, 主要有常绿针叶林, 落叶阔叶林及竹林等; 土壤类型南部以红壤为主、北部主要是 黄棕壤.

\section{2 数据来源与土地利用分类}

本研究以 1990 年、2000 年、2008 年 3 个时相的 LandsatTM (或 ETM ${ }^{+}$) 多光谱遥感影像图作为基础数据, 以太湖流域行政区划图、1:50000 水系图、1:50000 地形图等图件资料及统计资料、实地调研材料作为辅助资 料. 运用 RS 和 GIS 技术进行遥感影像预处理、辐射纠正、几何精校正与图像配准,在人机交换方式下进行目 视解译,建立土地利用信息数据库. 经同期土地利用详查资料和典型区野外实地抽样调查验证,解译精度达 到 $85 \%$ 以上. 基于全国土地资源分类系统, 以土地利用方式、景观特点及研究尺度特征为分类依据,采用 二级分类系统将区内土地利用划分为耕地、林地、草地、水域、建设用地、未利用地等 6 个一级类型以及水 田、旱地、有林地、灌木林、疏林地、水体、滩涂等 17 个二级类型. 根据区内土地利用分类情况,选取与之对 应的 6 种景观类型所代表的生态系统作为风险受体 ${ }^{[16]}$, 以 14 个县 (市) 区作为评价单元进行景观生态风 险计算.

\section{2 研究方法}

景观斑块的大小、斑块之间的连通度、斑块的多样性等既是自然和人类活动影响的结果, 又是影响区域 生态环境和生态过程的重要景观特征 ${ }^{[17]}$. 本文参考景观生态意义及相关典型研究案例 ${ }^{[18-20]}$, 选取破碎度指 数 $(C)$ 、分离度指数 $(S)$ 及优势度指数 $(D O)$ 等景观指数来定量表征景观结构和空间配置特征, 进而间接反 映人类活动对景观生态系统的干扰程度. 从景观干扰程度与生态系统脆弱性两方面构建景观格局与生态风 险关系式,定量评价太湖地区土地利用变化的景观生态风险及其空间差异. 具体公式如下:

$$
E R I=\sum_{i=1}^{n} \frac{S_{k i}}{S_{k}} \sqrt{E_{i} \times F_{i}}
$$


式中, $E R I$ 为景观生态风险指数, $n$ 为景观类型的数量, $S_{k i}$ 为第 $k$ 个风险小区第 $i$ 类景观组分的面积, $S_{k}$ 为第 $k$ 个风险小区的总面积. $E$ 为景观干扰度指数, 用来表征外界干扰程度, 计算公式为: $E_{i}=a C_{i}+b S_{\mathrm{i}}+c D O_{\mathrm{i}}(a=$ $0.5, b=0.3, c=0.2) ; F$ 为景观脆弱性指数, 根据研究区内 6 种景观生态系统实际情况, 分别赋以脆弱度值: 未利用地 $=6$ 、水域 $=5$ 、耕地 $=4$ 、草地 $=3$ 、林地 $=2$ 、建设用地 $=1$, 然后进行归一化处理, 得到各自的脆弱性 指数 ${ }^{[12]}$.

\section{3 结果分析}

\section{1 土地利用/覆被特点及其变化分析}

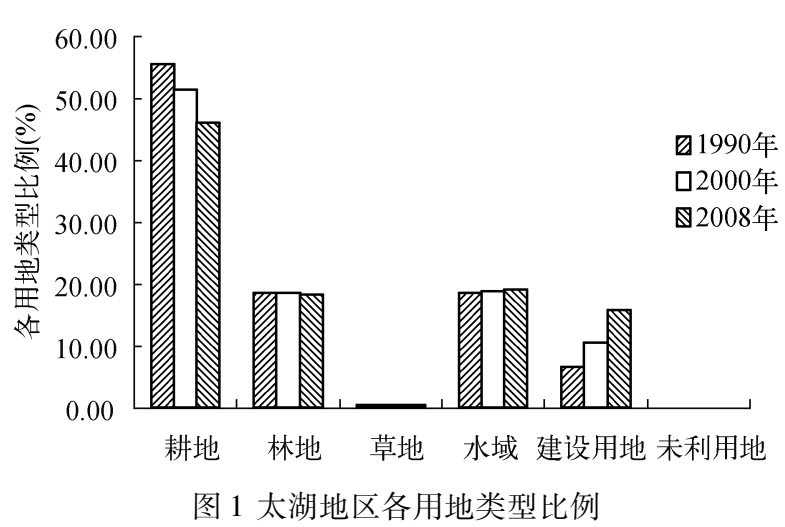

3.1.1 土地利用/覆被总体变化 $1990-2008$ 年间太湖地区土地利用/覆被变化显著, 最为 显著的是耕地的减少和建设用地的增加 (图 1).耕地一直是太湖地区的主导景观类型, 但 由于社会经济的发展, 大量农用地被开发或 占用, 耕地面积迅速减少, 已由 1990 年的 $11941.6 \mathrm{~km}^{2}$ 减少至 2008 年的 $9894.66 \mathrm{~km}^{2}$. 同 时随着城市化进程加快, 建设用地大面积扩 张, 平均每年增加约 $110.11 \mathrm{~km}^{2}$. 林地总体呈 现先增后降趋势, $1990-2000$ 年间, 林地面积 净增 $11.71 \mathrm{~km}^{2} ; 2000-2008$ 年间, 净减 $58.74 \mathrm{~km}^{2}$, 总计减少了 $47.03 \mathrm{~km}^{2}$. 水库、水渠 等水利工程兴建导致水域面积净增加

Fig. 1 The ratio of various land types in Taihu region

114. $27 \mathrm{~km}^{2}$. 草地和未利用地持续减少, 净缩减面积分别为 $4.54 、 13.01 \mathrm{~km}^{2}$. 从变化速率和幅度分析 (表 1 ), 区内土地利用经历了一个缓慢发展到显著变化的过程. 除水域外, 其他用地类型的变化速率均表现为 2000 - 2008 年快于 $1990-2000$ 年, 这与城市化及工业化发展进程相符合. 其中, 建设用地的开发幅度与变化速率 最为明显, 18 年间共计增涨了 $137.39 \%$, 主要表现为住宅用地与交通运输用地的快速扩展; 而耕地则以每年 $0.95 \%$ 的速率在减少; 未利用地、草地、水域、林地年变化率分别为 $-1.06 \% 、-0.21 \% 、 0.16 \% 、-0.07 \%$. 虽 然未利用地、草地面积减少总量不大, 但其变化幅度和变化速率较高, 对研究区内未利用地和草地景观基础 影响显著.

表 1 太湖地区 $1990-2008$ 年土地利用变化幅度及速率(\%)

Tab. 1 The change ranges and rates of land use in the Taihu region during 1990 and 2008(\%)

\begin{tabular}{|c|c|c|c|c|c|c|}
\hline \multirow{2}{*}{$\begin{array}{l}\text { 土地 } \\
\text { 类型 }\end{array}$} & \multicolumn{2}{|c|}{$1990-2000$ 年 } & \multicolumn{2}{|c|}{$2000-2008$ 年 } & \multicolumn{2}{|c|}{$1990-2008$ 年 } \\
\hline & 变化幅度 & 变化速率 & 变化幅度 & 变化速率 & 变化幅度 & 变化速率 \\
\hline 耕地 & -7.60 & -0.76 & -10.32 & -1.29 & -17.14 & -0.95 \\
\hline 林地 & 0.29 & 0.03 & -1.48 & -0.18 & -1.18 & -0.07 \\
\hline 草地 & -1.65 & -0.17 & -2.23 & -0.28 & -3.84 & -0.21 \\
\hline 水域 & 1.86 & 0.19 & 0.99 & 0.12 & 2.86 & 0.16 \\
\hline 建设用地 & 57.06 & 5.71 & 51.15 & 6.39 & 137.39 & 7.63 \\
\hline 未利用地 & -9.37 & -0.94 & -8.83 & -1.10 & -19.03 & -1.06 \\
\hline
\end{tabular}

3.1 .2 土地利用/覆被转移分析 运用 ArcGIS 空间分析模块, 通过地图代数运算法, 对土地利用数据进行统 计和叠加分析, 得到土地利用类型的转移矩阵. 18 年间, 耕地损耗量占减少总量的 $78.83 \%$. 其中, $1990-$ 2000 年, 耕地损耗量占耕地减少总量的 $36 \% ; 2000-2008$ 年, 损耗比例骤升至 64\%, 呈加速消耗趋势. 有 $81.49 \%$ 的耕地流向建设用地, 主要转化为城镇用地及工矿用地, 其次为农村居民点; 约 $11.47 \%$ 和 $6.51 \%$ 转 
为水体及林地. 建设用地一直呈现高开发态势, 其增加量占增加总量的 $69.42 \%$, 主要来源于水田和旱地, 其 次为林地和草地. 由此看来,城市化作用、交通建设用地增加与农业产业结构调整是建设用地增加与耕地减 少的主要原因. 此外,耕地、建设用地与林地、水域之间的相互转换也很剧烈, 林地转出面积的 $52.37 \%$ 流向 耕地, 37. $64 \%$ 转移为建设用地, 主要为临近道路两侧、居民地以及耕地附近的疏林地和灌木林的开剭; 而林 地增加面积的 $85.47 \%$ 源自 “退耕还林”,少量来自草地和建设用地. $1990 \mathrm{~s}$ 以来,湖泊围垦现象严重, 填湖造 地的 $96.32 \%$ 用于农田和城镇建设.

3.1 .3 评价单元土地利用情况 从土地利用组成结构看: (1) 研究区南部的苕溪流域以林地和耕地为主, 其 中,安吉县、长兴县、德清县林地比例高达 $67.58 \% 、 40.5 \%$ 、38.8\% . 该区城市化水平偏低,除余杭区和湖州 市区外,其余县(市) 区建设用地比例均低于 $10 \%$, 安吉县仅为 $4.1 \%$. (2) 位于研究区西侧的湖西平原因自 然本底与水热条件优良,农业较发达,丹阳市、溧阳市、金坛市等的耕地比重均超过 $60 \%$,但区内林地、水体 等自然景观比例较少. (3) 环湖地区经济发达, 人口密集,城市化水平远高于其他地区,建设用地与水体占 优势,其中, 常州、无锡以及苏州市区的建设用地比例分别占 $40.22 \% 、 37.22 \% 、 39.34 \%$ (未包括太湖水面)， 苏州市区的水域比例高达 $58.22 \%$ 。

从土地利用变化情况看,各县市的耕地面积持续减少,建设用地面积不断增加,其中常州、无锡和苏州 市区耕地面积减幅最为明显,分别减少 $33.87 \% 、 31.98 \% 、 28.67 \%$; 长兴县减幅最小,仅减少 $4.23 \%$. 安吉 县的建设用地增幅最大,为 $346.38 \%$, 净增加面积为 $60.06 \mathrm{~km}^{2}$, 其次为常州、苏州和无锡市区; 余杭区增 幅最小,为 $68.33 \%$. 综上所述,研究区内土地利用存在明显的空间差异, 城镇扩张与耕地蚌食主要集 中在“苏锡常”等地区社会、经济和文化中心. 此外,县域经济的快速发展也导致安吉等地建设用地明 显扩张。

\section{2 土地利用变化的景观生态风险评价}

3.2 .1 景观格局指数分析 通过计算得到研究 区 1990 年、2000 年、2008 年三个典型年的景观 格局指数变化情况 (图 2), 进而分析人类活动与 景观结构之间的关系.

(1) 破碎度指数是由单一、均质和连续的整 体趋向于复杂、异质和不连续的斑块镶嵌体的过 程,其变化与人类活动密切相关. 研究区景观斑 块数量由 1990 年的 17867 个增加至 2000 年的 18640 个,2008 年减少至 17641 个. 耕地、林地、 草地、水体及未利用地的破碎度持续增加, 建设 用地的破碎度有所降低,主要因城镇化过程中农 村居民点等零散斑块不断与城镇核心斑块合并 形成较大斑块,进而导致斑块数量减少, 破碎度 降低.

(2) 分离度指数指某一景观类型中不同斑 块个体之间的分离程度. 其变化情况与破碎度指
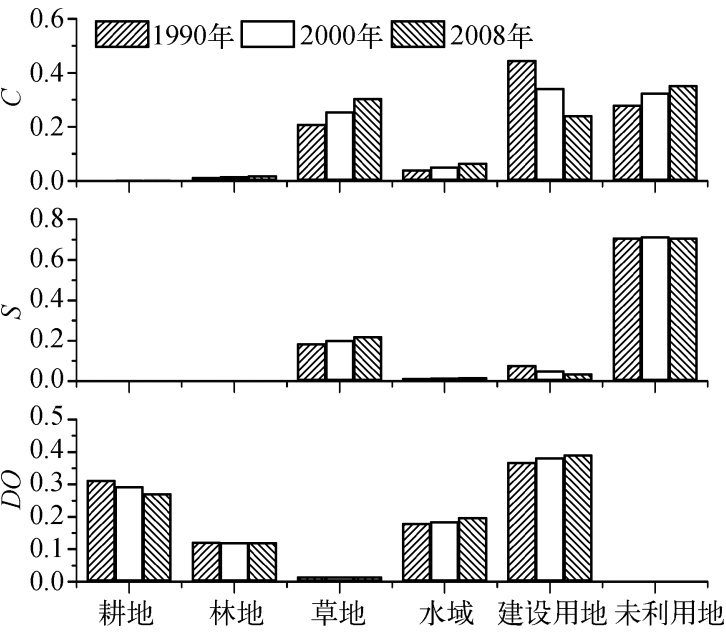

图 $21990-2008$ 年景观格局指数变化

Fig. 2 The change of landscape indices during 1990 and 2008

数基本一致. 未利用地、草地的分离度较大,而耕 地、林地、水域、建设用地的分离度相对较小,表明区域内景观分离度大小存在较大差异,在一定程度上反映 了人类活动强度对景观结构的影响,此外,还与景观类型的分布格局及面积有关.

(3) 优势度指数反映了少数景观类型占主导地位, 景观多样性与最大多样性之间的偏差. 耕地和建设 用地为研究区内的优势景观,但耕地优势度指数逐渐减小,而建设用地不断增大, 至 2008 年耕地优势度减 少至 0.027 , 而建设用地优势度增加为 0.039 , 说明区内自然、半自然景观改造程度较大,人工景观控制性增 强, 景观多样性降低.

3.2 .2 景观生态风险评价 由于太湖流域社会经济与自然环境特征存在明显差异,因此,风险源及其危害的 
作用结果在不同区域、不同地点可能是不同的. 为了能更好的表现太湖地区生态风险的时空变化特征,采用 ArcGIS 地域聚类法将景观生态风险指数划分为五个等级: 低生态风险 ( I : $0.00 \leqslant E R I<0.04)$ 、较低生态风 险 ( II : $0.04 \leqslant E R I<0.05$ )、中等生态风险 ( III : $0.05 \leqslant E R I<0.06$ )、较高生态风险 ( IV :0.06 $\leqslant E R I<0.07$ ) 和 高生态风险 $(\mathrm{V}: 0.07 \leqslant E R I<0.1)$.

(1) 景观生态风险演化的时序特征. 18 年间全区景观生态风险值由 0.0543 上升至 0.0625 , 风险增加了 $15.13 \%$, 生态风险等级也由中等生态风险升至较高生态风险. 通过统计各级景观生态风险比例得出 (图 3): 1990 年区内以较低生态风险为主, 占总面积的 $57.14 \%$, 中等生态风险所占比例为 $28.57 \%$, 较高生态风险 比例较少, 未出现低生态风险与高生态风险区. 与 1990 年相比,2000 年区内出现高生态风险, 较低生态风险 缩减了 $14.29 \%$, 而中等生态风险增加了 $14.29 \%$, 这是由丹阳市与湖州市区生态风险增加所致. 2008 年区 内以中等生态风险为主, 较低生态风险比例仍继续下降, 中等生态风险与较高生态风险范围不断扩大, 中等 生态风险区新增了宜兴市与安吉县, 较高生态风险区则增加了金坛市; 高生态风险比例维持不变, 但无锡市 区替代镇江市区成为新的高生态风险区. 这一时期各等级生态风险变化总体趋势为: 较低生态风险的范围 逐年缩小, 中等和较高风险分布范围不断扩大, 高生态风险从无到有呈增加态势.
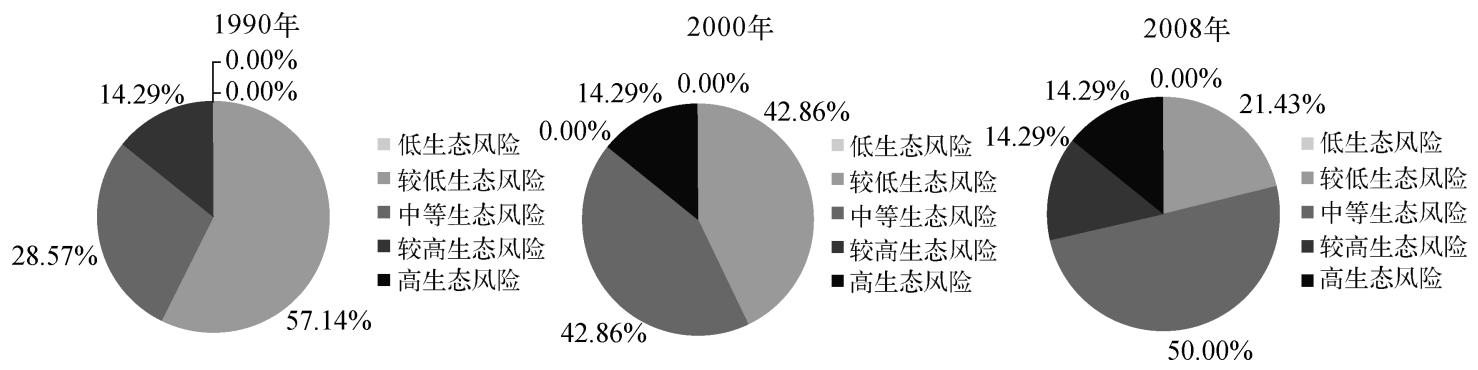

图 3 太湖地区典型年不同等级生态风险面积比例

Fig. 3 The proportion in different levels of ecological risk

纵观整个区域, 研究时期有 $78.57 \%$ 的区域景观生态风险指数逐渐增大, $14.29 \%$ 呈先增大后减少趋势, 7. 14\% 呈先减少后增加的趋势. 其中, $1990-2000$ 年间, 全区生态风险整体呈上升趋势, 增加速率为 $0.041 \%$. 除余杭区景观生态风险略有降低, 其余各区生态风险均有升高, 上升幅度最大的为常州市区, 约上 升 $14.59 \%$; 其次为苏州市区和镇江市区, 分别上升 $8.85 \%$ 和 8.46\%. $2000-2008$ 年间, 生态风险上升速率 为 $0.052 \%$, 明显高于前一阶段, 表明生态风险整体呈现加速上升的趋势. 除镇江市区及长兴市的生态风险 略有降低, 其余各区均有升高, 上升幅度最大的为无锡市区, 约为 $56.12 \%$; 其次为安吉县和宜兴市, 分别上 升了 $16.53 \%$ 和 $11.13 \%$.

(2) 景观生态风险的空间差异性. 研究区内景观生态风险的空间差异性显著, 整体呈现南低北高, 中间 低四周高的分布格局 (图 4). 较低生态风险集中于苕溪流域, 主要包括长兴县、德清县、安吉县、余杭区, 这一 区域属于太湖流域上游区, 分布有天目山山脉, 植被覆盖度高, 人口密度低, 土地开发利用程度远低于太湖 流域平均水平 ${ }^{[21]}$, 人为活动对景观干扰程度较轻, 景观破碎度小, 整体景观生态风险低于其他区. 但近年来, 安吉县、德清县生态风险有逐年增加趋势. 中等风险区主要分布在湖西平原的丹阳市、溧阳市、金坛市及环 湖带的苏州市区、吴江市等地. 这一带地势平缓, 自然条件优越, 人口密集, 土地利用程度和开发强度较大. 现代化的农业生产、城市的䓨延扩张、交通水利设施的建设对耕地、水域景观的割裂均增大了景观破碎程 度, 降低了景观连通性, 引起生态环境质量下降, 潜在生态风险增大. 较高风险区与高风险区主要出现在北 部的常州市区、无锡市区及镇江市区, 这是整个太湖流域经济最发达, 人口最稠密的地区之一, 人类活动频 繁, 城市化水平较高, 但尚未达到经济集约型增长阶段, 工矿用地的扩展在耕地及水域流失面积中占绝对比 例, 人工景观占主导, 自然景观急剧减少, 生态格局遭到破坏, 生态风险增大. 总体而言, 太湖地区景观生态 风险的时空演变符合这一时期人地发展规律. 


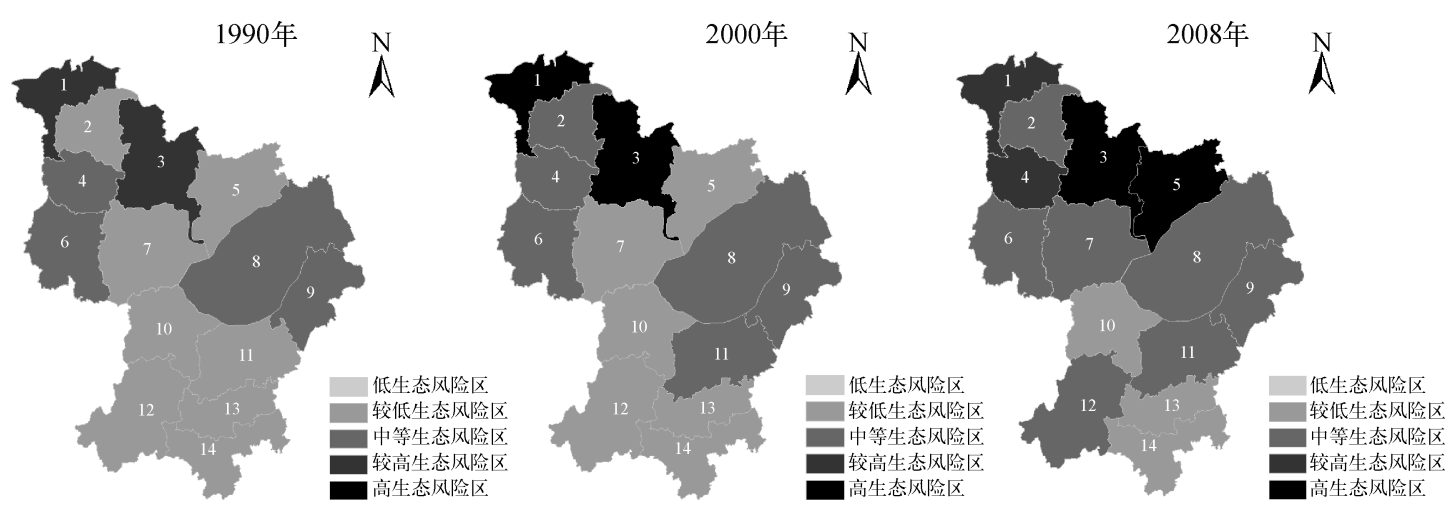

图 4 太湖地区景观生态风险的时空分布

Fig. 4 The temporal and spatial distribution of Landscape ecological risk in Taihu region

\section{4 景观生态风险来源及其影响因素}

受自然特征和社会经济发展等因素影响, 太湖流域生态风险来源较为复杂, 区域不同, 风险来源亦不 同. 土地利用方式及强度是人类干扰活动的最直接表现形式,因此,通过计算不同类型土地利用对景观生态 风险的贡献率得到不同区域景观生态风险的来源及其影响因素 (图 5), 主要包括: (1) 耕地大幅度减少与城 镇用地的迅猛增加, 使得具有较高生态意义的自然与半自然景观数量急剧下降, 人工景观优势度增强, 生物 多样性减少,进而导致生态风险增大. 主要包括镇江市区、丹阳市、常州市区、无锡市区、宜兴市等. (2) 河湖 水网等大水面的开发利用, 导致社会发展与生态保护关系失调. 围湖造田、围网养殖及水利设施的兴建等人 类活动干扰增强, 使得水体斑块数量增多、面积减少, 水域景观破碎度与分离度增强, 从而降低水生态系统 抵御外界干扰的能力, 阻碍了物种的迁移与扩散, 导致水域风险逐渐加大. 全区水体风险贡献率已由 1990 年的 $28.36 \%$ 增加至 2008 年的 $30.73 \%$. 主要包括苏州市区、吴江市、无锡市区、宜兴市、湖州市区等. (3) 人 口增长与城市发展迫使农田开垦、居民点建设逐渐从平原地区扩展到岗坡地、丘陵山地, 人类活动空间的无 序扩展造成了植被破坏, 林地破碎度和分离度急剧增大, 致使林地景观生态风险增加. 这是安吉县、德清县、 长兴县等丘陵山地区生态风险增加的主要原因之一. 此外, 林地风险的增加将直接导致水土流失风险的增 大. 综上所述, 各地区应根据风险来源采取差别化风险管理策略, 协调好经济发展、城市建设与生态环境之 间的关系,进而降低生态风险负效应, 实现生态风险最小化.

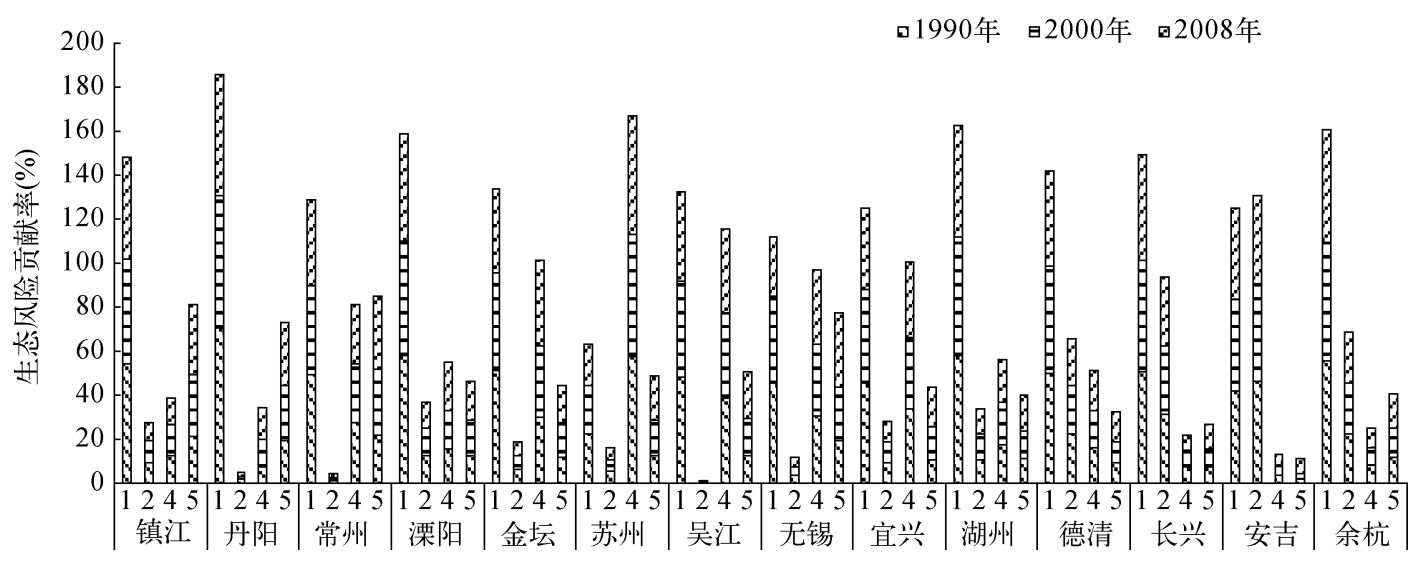

图 5 不同区域景观类型的生态风险贡献率 $(1$ : 耕地, 2 :林地, 3 :草地, 4 : 水域, 5 :建设用地)

Fig. 5 The contribution of the different landscape types to the ecological risk 


\section{5 结论}

在城镇化、工业化及区域经济发展过程中,太湖地区土地利用转换剧烈, 对区域景观结构与格局产生了 十分复杂的影响. 本研究构建的景观生态风险指数能够较好的定量评价区域生态环境状况, 并反映区域景 观生态风险演化方向, 可为区域生态环境管理提供决策依据和理论支持. 研究结果表明: (1) 太湖地区 18 年 间土地利用发生显著变化, 景观生态风险整体呈加快增涨趋势. 较低生态风险面积不断缩减, 中等生态风险 及较高生态风险的面积逐渐扩大. (2) 景观生态风险的空间差异显著, 较低生态风险主要分布于苕溪流域 的山地丘陵区; 中等生态风险范围较广, 主要分布于平原区; 较高生态风险及高生态风险主要集中于沿湖经 济发达区. (3) 生态风险来源具有一定区域特征, 不同区域景观生态风险来源不尽相同. 耕地与建设用地是 全区生态风险的主要来源, 水域和林地的景观生态风险贡献率越来越大.

\section{6 参考文献}

[1] 曾 辉,刘国军. 基于景观结构的区域生态风险分析. 中国环境科学, 1999,19(5):454-457.

[2]许学工, 林辉平, 付在毅等. 黄河三角洲湿地区域生态风险评价. 北京大学学报 (自然科学版), 2001, 37 (1): 111-120.

[ 3 ] Hunsaker CT, Graham RL, SuterGW II et al. Assessing ecological risk on regional scale. Environmental Management, $1990, \mathbf{1 4}(3)$ : 325-332.

[ 4 ] Graham RL, Hunsaker CT, $\mathrm{O}^{\prime}$ Neil RV. Ecological risk assessment at the regional scale. Ecological Applications, 1991, 1 (2) : 196-206.

[5]李景刚, 何春阳, 李晓兵. 快速城市化地区自然/半自然景观空间生态风险评价研究——北京为例. 自然资源学 报, 2008,23(1):33-47.

[ 6 ] 肖笃宁,布仁仓,李秀珍.生态空间理论与景观异质性. 生态学报, 1997,17 (5):453-461.

[ 7 ] 陈佑启,杨 鹏. 国际上土地利用/土地覆盖变化研究的新进展. 经济地理, 2001,21(1): 95-100.

[ 8 ] Kapustka LA, Galbraith H, Luxon M. Using landscape ecology to focus ecological risk assessment and guide risk management decision-making. Toxicology and Industrial Health, 2001, 17: 236-246.

[ 9 ] Liu SL, Cui BS, Yang ZF. Evaluating the influence of road networks on landscape and regional ecological risk-A case study in Lancang River Valley of Southwest China. Ecological Engineering, 2008, 34(2) : 91-99.

[10] 肖 杨,毛显强. 区域景观生态风险空间分析. 中国环境科学,2006,26(5):623-626.

[11] 曾 勇. 区域生态风险评价一以呼和浩特市区为例. 生态学报, 2010,30(3):668-673.

[12] 谢花林. 基于景观结构和空间统计学的区域生态风险分析. 生态学报, 2008,28(10):5020-5026.

[13] 荆玉平,张树文,李 颖. 基于景观结构的城乡交错带生态风险分析. 生态学杂志,2008,27(2):229-234.

[14] 陈 鹏, 潘晓玲. 干旱区内陆流域区域景观生态风险分析一以阜康三工河流域为例. 生态学杂志, 2003, 22 (4): 116-120.

[15] 高永年, 高俊峰, 许 妍. 太湖流域水生态功能区土地利用变化的景观生态风险效应. 自然资源学报, 2010,25(7): 1088-1095.

[16] 胡魏㙁, 王根绪, 邓 伟. 景观格局与生态过程相互关系研究进展. 地理科学进展, 2008, 27 (1) : 18-24.

[17] 史培军, 江 源, 王静爱. 土地利用覆盖变化与生态安全响应机制. 北京: 科学出版社, 2003:5-6.

[18］傅伯杰.黄土区农业景观空间格局分析.生态学报,1995,15(2):113-120.

[19］邬建国. 景观生态学——格局、过程、尺度与等级. 北京:高等教育出版社, 2000:100-108.

[20] 王 娟,崔保山, 刘 杰等. 云南澜沧江流域土地利用及其变化对景观生态风险的影响. 环境科学学报, 2008, 28 (2) :269-277.

[21]许刚, 朱振国, 解晓南. 太湖流域上游土地利用变化机制的实证分析一一以浙江省安吉县为例. 湖泊科学, 2004, 16(2) : 149-156. 